\section{Erupted compound odontoma: case report of a 15-year-old Sudanese boy with a history of traditional dental mutilation}

\author{
P. Amailuk ${ }^{1}$ and D. Grubor ${ }^{2}$
}
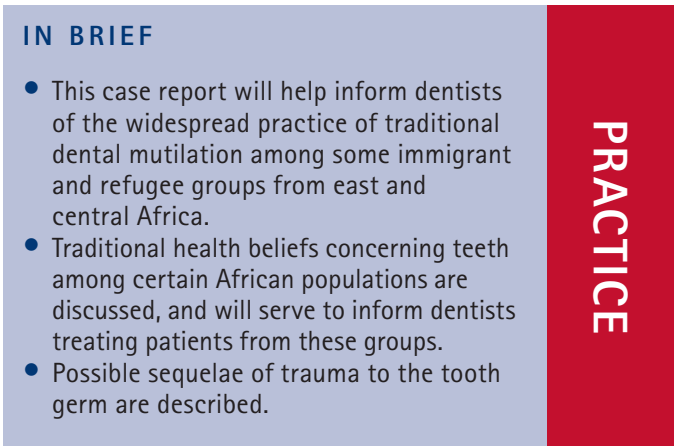

\begin{abstract}
A rare case of an erupted compound odontoma associated with a malformed and dilacerated maxillary left lateral incisor is reported. The patient, a 15-year-old immigrant Sudanese boy, had a malformed right lateral maxillary incisor and missing centrals. His guardian reported he had undergone traditional extraction of his primary teeth as a child whilst in Africa. Treatment and possible mechanisms for development of the condition are discussed. The number of refugees and migrants from Africa to developed countries has increased in the past 20 years. Australia in particular with its large population of recent migrants from areas in Africa where tooth mutilation is practised will likely see more patients with dental abnormalities in the respective populations.
\end{abstract}

\section{INTRODUCTION}

Odontomas are the most common benign odontogenic tumours of epithelial and mesenchymal origin. ${ }^{1}$ The World Health Organisation (WHO) defines odontomas as two types: ${ }^{2}$ Complex Odontomas, a malformation in which all dental tissues are present, but arranged in a more or less disorderly pattern; and Compound Odontomas, a malformation in which all of the dental tissues are represented in a pattern that is more orderly than that of the complex type. ${ }^{3}$ Enamel, dentine, cementum and pulp are arranged as they would be in the normal tooth. ${ }^{4}$

The cells of the tissues in odontomas are normal but lack organisation due to disordered expression and localisation of the extra-cellular matrix molecules in the dental mesenchyme. ${ }^{4,5}$ Odontomas are considered hamartomas whose aetiology is still unknown. ${ }^{6}$

Odontomas erupting into the oral cavity are extremely uncommon, the first

\footnotetext{
${ }^{1 *}$ Resident, Deptartment of Oral Surgery, ${ }^{2}$ Consultant Oral and Maxillofacial Surgeon, Head of Department of Oral Surgery, Royal Dental Hospital of Melbourne, 720

Swanston St., Carlton, Vic 3053, Australia

${ }^{*}$ Correspondence to: Dr Paul Amailuk

Email: paulamailuk@yahoo.co.uk
}

\section{Refereed Paper}

Accepted 25 September 2007

DOI: $10.1038 /$ bdj.2007.1184

${ }^{\oplus}$ British Dental Journal 2008; 204: 11-14 case being reported in English literature in 1980 by Rumel et al., ${ }^{7,8}$ A literature review by Litonjua et al. in 2003 recorded only 14 cases in English literature ${ }^{9-12}$ from 1980 to 2003. In March 2007 Vengal et al. ${ }^{13}$ reported a case in Canada. of particular interest in our case is the possible relationship of the malformation to traditional tooth extraction performed on the patient as a young child.

\section{CASE REPORT}

A 15-year-old Sudanese Dinka boy was referred to the Oral Surgery department of the Royal Dental Hospital of Melbourne by his general dentist for extraction of an upper left central incisor and its associated odontoma. The appearance of his teeth was a concern but he had no complaint of pain or previous infection.

He had moved to Australia in 2006 as a refugee. His first year of life had been in southern Sudan followed by 13 years in a refugee settlement in Northern Uganda. He migrated to Australia as an unaccompanied minor. The patient's guardian, an older cousin, reported that the affected teeth had erupted looking 'abnormal'. He was unsure as to exactly what age the tooth eruption took place. There was no history of trauma to the facial region as a child, but traditional extractions had been performed. The patient's guardian stated that the practice of removing erupting primary teeth was common amongst the Dinka people. He believed that traditional tooth removal was carried out on the patient as a toddler, though he was unsure as to exactly what age this would have been done.

The patient was fit and well medically. Extraoral examination was unremarkable. He was missing both his maxillary right and his left central incisor. The crown of the maxillary right lateral incisor was malformed with a large tooth-like mass approximately $2 \mathrm{~cm}$ in diameter in the area occupied by the maxillary left lateral incisor. The crown of the maxillary left lateral incisor appeared to be lateral to and attached to the mass, which was slightly mobile. (Fig. 1)

Periapical, OPG and maxillary occlusal (Fig. 2) radiographs were taken. The OPG demonstrated the presence of a large radiopaque mass in the region of the maxillary left lateral incisor. A periapical radiograph appeared to show a second separate mass in the area of the maxillary left central incisor. What appeared to be a compound odontoma superimposed over the maxillary left lateral incisor was evident on the maxillary occlusal film. The root of the maxillary left lateral incisor demonstrated severe dilaceration, but a normal periodontal ligament. The maxillary right 
lateral incisor appeared to show normal root development.

A compound odontoma with malformation of the crowns of the maxillary right lateral, and maxillary left lateral incisor (including dilaceration) was the provisional diagnosis. The treatment plan involved extraction of the maxillary left lateral and the associated odontoma with curettage of the area. It was decided to leave the maxillary right lateral incisor and refer the patient to a general dentist to have the crown recontoured with restorative materials.

Following infiltration of local anaesthesia (2\% lignocaine 1:80,000 adrenaline) the mass in and the area of the maxillary left lateral incisor was luxated using forceps. Two distinct masses were present (Fig. 3). The first was what appeared to be a compound odontoma in the region of the maxillary left central incisor, the second a severely dilacerated maxillary left lateral incisor with an odontoma-like malformation of the crown. The extraction socket appeared normal. The area was curetted and closed with plain 3.0 catgut and the extracted tooth and mass were sent to the pathology department. Healing of the site was uneventful and the patient was referred to a general dentist for restorative and prosthodontic care. The authors do not know what prosthetic treatment option was decided upon.

\section{PATHOLOGY REPORT}

The sections showed both a tooth like and haphazard arrangement of dental hard and soft tissue including cementum, dentine, enamel matrix, pulp and periodontal tissue (Fig. 4). The pathology report was consistent with a compound odontome.

\section{DISCUSSION}

The eruption of odontomas is infrequent and in the literature seven of these have been compound type. ${ }^{9,10,14}$ Pain and swelling are the most common symptoms when odontomas erupt, followed by malocclusion. ${ }^{1}$ Recurrent infection following eruption into the oral cavity has been reported ${ }^{9}$ but did not occur in this case. The patient had no complaint apart from the undesirable appearance. Compound odontomas are more common

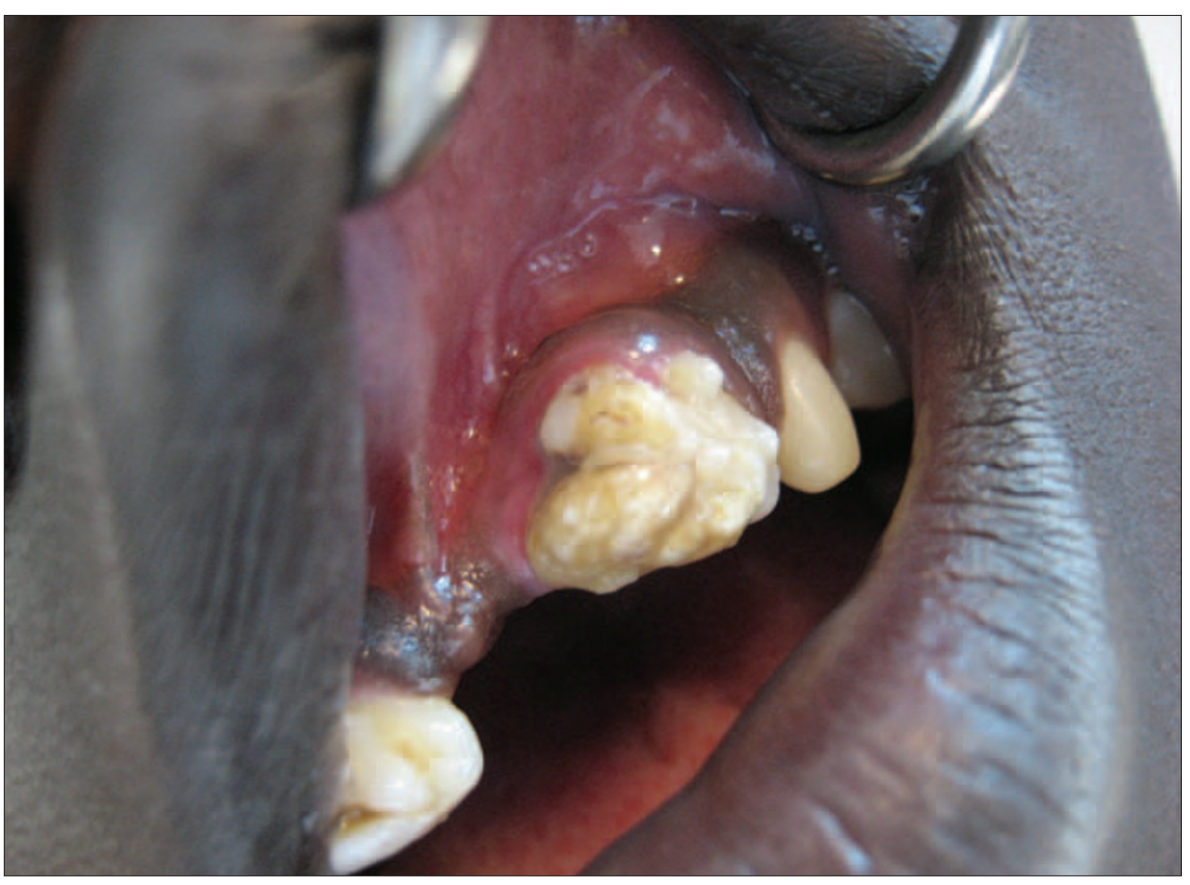

Fig. 1 Preoperative intra-oral view of mass



Fig. 2 Maxillary occlusal radiograph

in the anterior of the oral cavity whilst complex odontomas are more common in the posterior mouth.

Where surgical management is necessary, standard treatment consists of removal of the lesion and enveloping soft tissue with curettage. This is to prevent the possibility of cystic degeneration. ${ }^{2}$ Dentigerous cysts, odontogenic keratocysts and calcifying odontogenic cysts have been associated with odontomas. ${ }^{15}$ Once the odontoma is removed surgically along with any lining epithelium, there is usually no recurrence. In this patient's case, there was no evidence of cyst formation.

The majority of odontomas are associated with impacted teeth. Chang et $a l .{ }^{16}$ found that the maxillary central incisor was most commonly involved. In this case, but the development of the maxillary right and left central incisors were affected.

Though the exact aetiology of odontoma formation is unknown, a number of factors including prior trauma and infection seem to be involved. ${ }^{9}$ A case of compound odontoma associated with a 
history of trauma in the anterior region of the face in a 10-year-old was reported by Iturri et al. ${ }^{17}$

Odontoma-like malformation is an anomaly that affects permanent teeth after trauma to the primary dentition. It has been described as a mass of mineralised tissue slightly similar in structure to a normal tooth and may have a relatively normal or rudimentary root. ${ }^{18}$

Our patient had a history of traditional mutilation by tooth extraction as a child either in southern Sudan or northern Uganda. This custom has been described in the literature $\mathrm{e}^{19,20}$ amongst the peoples of the region of Africa where the patient spent the majority of his life. An incidence rate of traditional mutilation by tooth extraction as high as $16 \%$ of children in northern Uganda, 22\% amongst urban Sudanese and 100\% in a southern Sudanese hospital was reported by Elinor et al. ${ }^{19}$ Iriso et al. ${ }^{21}$ recorded traditional tooth extraction complications as one of the leading causes for hospital admission, morbidity and death in the paediatric ward of a large referral hospital in northern Uganda. There appears to be a strong cultural belief that the swelling in the area of the gums during eruption of the primary teeth (canines in particular) was a cause of persistent fever and diarrhoea. The historical origins of the procedure are not clear but appear to be spread over several countries in East Africa including Somalia, Ethiopia, Sudan, and Uganda. ${ }^{22}$ A traditional healer is consulted to lance or remove this area of the gums. The age at which the lancing or extraction is carried out varies from as early as one month to three years with peak ages from most studies between four months to 18 months. This age coincides with the age of hard tissue formation in the crowns of the maxillary permanent central and lateral incisors (three months to five years and 11 months to five years respectively) ${ }^{23,24}$ as well as the eruption of the primary maxillary incisors and 'gum swelling' (6-10 months).

The tooth extractions are carried out by untrained traditional healers often using unsterilised instruments and no anaesthesia. ${ }^{25}$ The permanent incisors are often affected..$^{20,26,27}$ The procedure is considered a 'success' if the 'tooth worm' is removed along with the primary cuspid. The 'tooth worm' is the dental lamina of the permanent canine, before crown development. If the dental lamina is not removed, it may continue to develop normally, although it is more likely damaged, resulting in a dysplastic or deformed permanent tooth. Abnormalities in the permanent dentition are the primary oral consequence of the practice. ${ }^{19}$

A case of a small odontoma developing at the site of a mandibular canine extracted early in childhood by a traditional healer was reported in an Ethiopian teenager who resides in Sweden, ${ }^{28}$ and in a Somali teenager residing in the United States. ${ }^{19}$

Damage to the permanent maxillary incisor tooth buds and subsequent odontoma/odontoma-like malformation is an entirely possible consequence of this traditional practice in our patient.

Dilaceration commonly occurs in permanent incisors as a result of trauma to the primary predecessors, whose apices lie close to the permanent tooth germ. The calcified portion (crown) of the permanent tooth germ is then displaced in such a way that the remainder of the tooth is formed at an angle. ${ }^{29}$

The coincidence of compound odontoma and root dilaceration is extremely rare $^{30}$ but has been reported in literature.

In this patient the odontoma was labially positioned and attached to a malformed upper left lateral incisor whose root dilaceration was in a mesio-palatal direction. The physical presence of the odontoma may have influenced the direction of root development and led to angulation and or dilaceration in this case.

\section{SUMMARY/CONCLUSION}

A rare case of an erupted compound odontoma associated with a malformed and dilacerated lateral maxillary incisor has been reported. Of interest is the association of the malformation of the teeth and the patient's history of a traditional tooth mutilation incident as a child. The number of refugees and migrants from Africa to developed countries has increased in the past 20 years. Australia in particular with its large population of recent migrants from

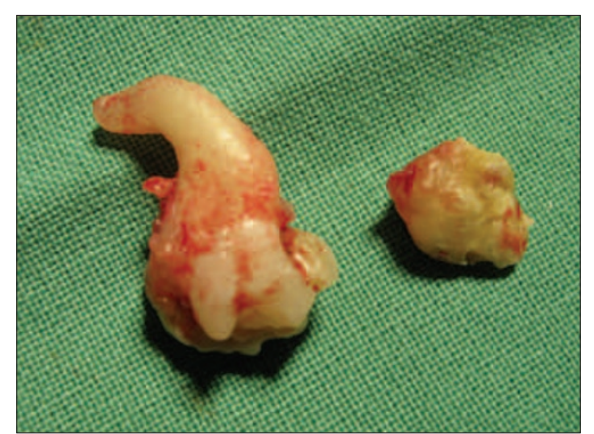

Fig. 3 Extracted masses and associated tooth

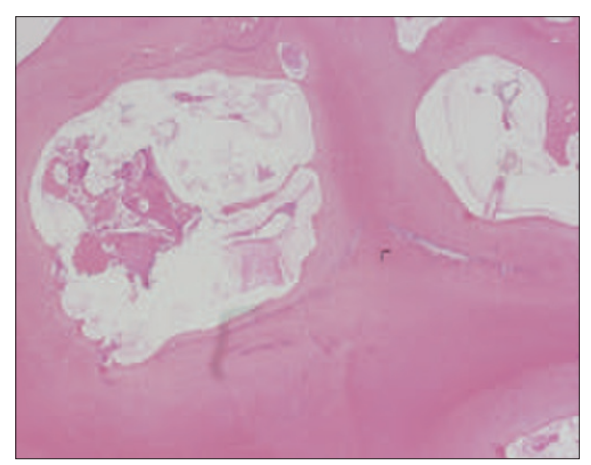

Fig. 4 Photomicrograph of extracted tissue

areas in Africa where tooth mutilation is practiced will likely see more patients with dental abnormalities in the respective populations.

The authors would like to acknowledge Dr Chris Angel, School of Dental Science, Faculty of Medicine, University of Melbourne.

1. Budnick S. Compound and complex odontomas. Oral Surg Oral Med Oral Pathol 1976; 42: 501-506. 2. Phillipsen H, Reichardt P, Praetorious F. Mixed odontogenic tumours and odontomas. Considerations on interrelationship. Review of literature and presentation of 134 new cases of odontomas. Oral Oncol 1977; 33: 86-99.

3. Kramer I, Pindborg J, M S. Histological typing of odontogenic tumours. New York: Springer-Verlag, 1992

4. Ida-Yanemochi H, Noda T, H S, T S. Disturbed tooth eruption in osteopetrotic (op/op) mice: histopathogenesis of tooth malformation and odontomas. J Oral Med Oral Pathol 2002; 31:361-373.

5. Yanemochi H, Noda T, Shimokawa H, Saku T. Immunohistochemical localisation of extracellular matrix molecules in complex odontoma. Dent Jpn 1999; 35: 13-19.

6. Gnepp D. Diagnostic surgical pathology of the head and neck. Philadelphia: WB Saunders Co, 2001.

7. Ramel A, de Freitas A, Birmar E et al. Erupted complex odontoma: report of a case. Dentomaxillofac Radiol 1980; 9: 5-9.

8. Litonjua L, Suresh L, Valderrama L, Neiders M. Erupted complex odontoma: a case report and literature review. Gen Dent 2004; 52: 248-251.

9. Ferrer Ramirez M, Silvestre Donat F, Torres-Gomez F J, Avella-Vecino F, Salazar-Fernandez C. Recurrent infection of a complex odontoma following eruption in the mouth. Med Oral 2001; 6: 269-275

10. Rumel A, de Freitas A, Birmar E et al. Erupted complex odontoma: report of a case. Dentomaxillofac Radiol 1980; 9: 5-9.

11. Ajike $S$, Adelaye E O. Multiple odontomas in the facial bones: a case report. Int J Oral Maxillofac Surg 2000; 29 : 443-444. 
12. Ragalli C, Ferreira J, Blasco F. Large erupting complex odontoma. Int J Oral Maxillofac Surg 2000. 29:373-374.

13. Vengal M, Arora H, Ghosh S, Pai K. Large erupting complex odontoma: a case report. J Can Dent Assoc 2007: 73: 169-173.

14. Birbaum M, Tyrangel A, S M S. Exfoliated odontoma. Oral Surg Oral Med Oral Pathol 1980; 49: 96.

15. Kaugers G, Miller M, Abbey L. Odontomas. Oral Surg Oral Med Oral Pathol 1989; 67: 172-176.

16. Chang J Y, Wang J T, Wang $Y$ P et al. Odontoma: a clinicopathologic study of 81 cases. J Formos Med Assoc 2003: 102: 876-882

17. Samano Iturria G, Cedeno Pacheco E. Compound odontoma with history of trauma: a report of a case. Pract Odontol 1988; 9: 18-20.

18. Nelson-Filho P, Silva R, Faria G, Freitas A C. Odontoma-like malformation in a permanent maxillary central incisor subsequent to trauma to the incisor predecessor. Dent Traumato/2005; 21:309-312.

19. Elinor A G, Domoto P K, Lynch H, Egbert M. Dental injuries due to African traditional therapies for diarrhea. West J Med 2000; 173: 135-137.

20. Baba S, Kay E J. The mythology of the killer decidous canine tooth in Southern Sudan. J Pedod 1989; 14: 48-49.

21. Iriso R, Accorsi S, Akena S et al. 'Killer' canines: the morbidity and mortality of ebino in northern Uganda. Trop Med Health 2000; 5: 706-710.

22. Kikwilu E N, Hiza J F. Tooth bud extraction and rubbing of herbs by traditional healers in Tanzania: prevalence, and sociological and environmental factors influencing the practices. Int J Paediatr Dent 1997; 7: 19-24.

23. Borum M K, Andreasen J 0. Sequelae of trauma to primary maxillary incisors. I. Complications in primary dentition. Endod Dent Traumato/ 1998; 14:31-44.
24. Cameron A C, Widmer R P. Handbook of paediatric dentistry. Mosby, 2003

25. Halestrap D. Indigenous dental practice in Uganda. BrDent J 1971; 131: 463-466.

26. Pindborg J. Dental mutilation and associated abnormalities in Uganda. Am J Phys Anthropol 1969; 31:383-390.

27. Welbury R, Nunn J, Gordon P, Green-Abate C. 'Killer' canine removal and its sequelae in Addis Ababa. Quintessence Int 1993; 24:323-327.

28. Erlandsson A L, Backman B. A case of dental mutilation. ASDC J Dent Child 1999; 66:278-279, 229.

29. Kilpatrick N M, Itaduna P J, Welbury R. Dilaceration in a primary tooth. Int J Paediatr Dent 1991; 1: 151-153.

30. Yeung K H, Chueng R C, Tsang M. Compound odontoma associated with an unerupted and dilacerated maxillary primary central incisor in a young patient. Int J Paediatr Dent 2003; 13: 208-212. 